\title{
Evaluation of mechanical properties of several dual-cure resin cements by curing modes
}

\author{
Soo-Yeon Kim, Se-Hee Park, Jin-Woo Kim, Kyung-Mo Cho* \\ Department of Conservative Dentistry, College of Dentistry, Gangneung-Wonju National University, Gangneung, Republic of \\ Korea
}

Purpose: The purpose of this study was to evaluate the mechanical properties of several dual-cure cements by different curing modes. Materials and Methods: One resin-modified glass ionomer cement (FujiCEM 2), two conventional dual-cure resin cements (RelyX ARC, Multilink N), and two dual-cure self-adhesive resin cements (RelyX U200, G-CEM LinkAce) were used. To evaluate the influence of the curing methods, each cements divided into four conditions $(n=20)$; Condition 1: self-curing for 10 minutes, Condition 2: immediate after 20 seconds light-curing, Condition 3: 24 hours after self-curing, Condition 4: 24 hours after lightcuring. The compressive strength and diametral tensile strength were measured with a universal testing machine. All data were statistically analyzed using $t$-test, one-way ANOVA and Scheffe's test. Results: The results showed the compressive strength and diametral tensile strength after 24 hours in all curing modes were higher than immediate except RelyX ARC light-cured and Multilink $\mathrm{N}$ light-cured. The FujiCEM 2 showed lowest values $(P<0.05)$. Conclusion: The outcome was cement-depend, but there is no significant difference about compressive strength and diametral tensile strength between dual-cure self-adhesive resin cements and conventional resin cements. And this result will be used as a base line data selecting resin cement for favorable long-term prognosis. (J Dent Rehabil Appl Sci 2015;31(1):1-9)

Key words: resin cement; dual-cure; self-adhesive; compressive strength; diametral tensile strength; curing modes

\section{서론}

주조수복물의 유지와 수명은 형성된 와동의 경사도, 응력 분산을 고려한 와동 설계, 수복물 내면의 표면 조 도, 치질과 수복물에 대한 시멘트의 미세기계적 혹은 화 학적 결합, 시멘트의 종류 등의 복합적인 요소에 영향을 받는다.

치과용 접착 시멘트는 고정성 수복물과 삭제된 치아 사이를 연결해주는 역할을 하며, ${ }^{2}$ 수년동안 따뜻하고 습 한 구강 환경에서 저작압과 비기능성 스트레스를 견디어 수복물을 장기간 안정적으로 유지해야 한다. ${ }^{3}$ 즉 구강 내

*Correspondence to: Kyung-Mo Cho

Professor, Department of Conservative Dentistry, College of Dentistry, Gangneung-Wonju National University, 7, Jukheon-gil, Gangneung, 210-702, Republic of Korea

Tel: +82-33-640-3155, Fax: +82-33-640-3103, E-mail: drbozon@gwnu.ac.kr Received: October 27, 2014/Last Revision: February 3, 2015/Accepted: January 8,
에서 용해도가 낮아야 하고, 기계적 유지와 화학적 결합 에 의하여 치아 또는 수복물과 시멘트 사이의 결합력이 높아야 하며, 수복물과 치아 사이의 계면에서 응력에 저 항할 수 있는 강도와 파괴인성을 가져야 한다. 또한 사용 도 편리하고 생체적합적이어야 한다. ${ }^{4}$ 그러나 구강내 스 트레스는 시멘트의 회복 가능한 탄성 혹은 영구적인 소 성 변형을 일으키고 변연 파절 또는 변색, 치아의 2차 우 식 등을 발생시켜 수복물의 유지에 악영향을 미친다. ${ }^{5,6}$

과거에는 인산아연 시멘트(zinc phosphate cement), 폴 리카복실레이트 시멘트(polycarboxylate cement), 글래스 아이오노머 시멘트(glass ionomer cement)와 같은 시멘 
트들이 주로 사용되었지만 최근 들어 복합레진과 도재 등 심미적인 수복재료들의 사용이 점차 증가되면서부터 심미적이고 물리적 화학적으로 특성이 우수한 레진 시 멘트의 사용도 더불어 증가하고 있는 추세이다. ${ }^{1}$

레진 시멘트는 ANSI/ADA 규격 제 27호(ISO 4049) 에서 중합 방법에 따라 자가중합형, 광중합형, 이중중합 형으로 분류될 수 있다. 광중합형은 사용시 술자에 의한 시간 조절이 가능하다는 장점을 가지고 있으나, 주조수 복물에 사용될 때 시멘트의 모든 부분으로 충분한 빛에 너지가 도달될 수 없는 단점이 있다. ${ }^{7}$ 하지만 이중중합 형은 빛이 도달되지 않는 부분에서도 중합이 일어날 수 있으며 술자에 의해 중합을 조절할 수 있는 장점을 가지 고 있어 널리 이용되고 있다. 최근에는 치아 및 수복물 에 전처리가 필요없는 다양한 이중중합 자가접착 레진 시멘트가 소개되어 지속적으로 기존 제품보다 향상된 상품을 출시하고 있다. ${ }^{8}$

압축강도는 압축력에 대한 재료의 저항력을 측정하는 것으로 아말감이나 시멘트 등의 취성재료 및 압축에 대 한 저항성이 요구되는 재료에서 재료의 강약을 비교하 기 위해 측정한다. 그리고 간접인장강도는 인장시험이 용이하지 않는 취성재료에서 인장강도를 측정하는 간단 하고 재현성있는 방법이다. ${ }^{4}$ 취성이 있는 레진 시멘트의 압축강도와 간접인장강도가 강할수록 시멘트의 변형이 적고, 파절 저항이 높으며, 고르게 스트레스를 분산하고, 인장 또는 압축 실패의 위험도 줄며, 안정적이어서 임상 적으로 성공확률을 높여주기 때문에 이러한 특성을 평 가하고 이를 바탕으로 품질을 향상시켜서 임상에 사용 하려는 노력이 필요하다. ${ }^{9}$

이상적인 접착 시멘트의 중요한 요구조건 중 하나 는 기능적 저작력에 저항하는 뛰어난 기계적인 성질 을 제공해 주는 능력이다. 지금까지 여러 접착 시멘트 들의 flexural strength, ${ }^{10,11}$ hardness, ${ }^{12}$ diametral tensile strength, ${ }^{12,13}$ modulus of elasticity, ${ }^{14}$ fracture toughness ${ }^{15}$ 등 다양한 기계적 특성들이 조사 및 연구되어 결과가 보 고되고 있다. 하지만 현재 최근 출시된 레진 시멘트 제 품에 관한 기계적 성질에 대한 연구는 아직 부족한 상 황이다. 따라서 본 연구는 기존에 출시된 제품에서 최근 업그레이드되어 시판되고 있는 레진 시멘트 제품과 기 존에 출시된 레진 시멘트의 기계적 성질 중에서 압축강 도와 간접인장강도를 측정하여 비교 평가하고자 하였 다.

\section{연구 재료 및 방법}

\section{1. 실험 재료}

이번 연구를 위해 3 가지 다른 유형의 5 가지 시멘트를 사용하였다. 대조군으로 하나의 레진강화형 글래스아 이오노머 시멘트인 FujiCEM 2 (GC Co., Tokyo, Japan), 2개의 전통적인 이중중합 레진 시멘트인 RelyX ARC (3M ESPE, St. Paul, MN, USA)와 Multilink N (IvoclarVivadent, Schaan, Liechtenstein), 2개의 이중중합 자가 접착 레진 시멘트인 RelyX U200 (3M ESPE)과 G-CEM LinkAce (GC Co.)를 사용하였다. 각 시멘트의 구성성분 은 Table 1에 나타내었다.

\section{2. 실험군 분류}

2개의 전통적인 이중중합 레진 시멘트인 RelyX ARC 와 Multilink N, 2개의 이중중합 자가접착 레진 시멘트 인 RelyX U200과 G-CEM LinkAce)를 다시 각각 4가지 조건 즉, 자가중합과 광중합에서 각 subgroup으로 즉시 와 24시간으로 나눠 각각 20개씩의 시편으로 나닜다. 따 라서 각 시멘트 군당 총 80 개의 시편을 제작하였다. 하 지만 대조군으로 사용한 FujiCEM 2는 자가중합 과정에 서만 즉시와 24시간으로 나눠 시편을 각각 20개씩 총 40 개의 시편을 제작하였다. 결과적으로 총 실험군 수는 18 개 이다(Table 2).

\section{3. 시편 제작}

기계적 특성을 측정하기 위한 시편을 제작하기 위해 평가방법은 ISO Specifications 9917-1:2007에 의한 기 준에 의하여 설계하였다. ${ }^{16}$ 테플론을 이용하여 압축강도 를 위해 직경 $4 \mathrm{~mm}$, 높이 $6 \mathrm{~mm}$, 간접인장강도를 위해 직경 $6 \mathrm{~mm}$, 높이 $3 \mathrm{~mm}$ 인 시편을 제작하였다. 각각의 시멘트는 제조사의 지시에 따라 혼합하였다. 각 시멘트 를 주형에 채워 mylar strip으로 덮은 뒤 유리판으로 누 른 다음 즉시 자가중합은 온도 $37 \pm 1$, 상대습도 $100 \%$ 를 유지하는 빛이 들어가지 않는 항온기(SIB-1, SeoKwang Science Co., Seoul, Korea)에서 10분간 넣어 중 합하였고, 바로 강도를 측정하였다. 24시간 자가중합은 항온기에 넣고 24시간동안 중합시킨 후 강도를 측정하 였다. 광중합은 자가중합과 같이 시멘트를 주형에 채우 
Table 1. Composition of materials used in this study

\begin{tabular}{|c|c|c|c|}
\hline Material & Manufactures & Type & Composition \\
\hline FujiCEM 2 & GC & $\begin{array}{l}\text { Resin-modified } \\
\text { glass ionomer }\end{array}$ & $\begin{array}{l}\text { Paste A: Alumino-fluoro-silicate glass (amorphous), Hydroxyethyl } \\
\text { methacrylate, Dimethacrylate, Bis(4-methacryloxy ethoxyphenyl)pro- } \\
\text { pane (Bis-MEPP), Silicon Dioxide, pigment } \\
\text { Paste B: Polyacrylic acid, Distilled water, Silicone dioxide, Initiator }\end{array}$ \\
\hline RelyX U200 & 3M ESPE & $\begin{array}{l}\text { Dual-cure } \\
\text { Self-adhesive }\end{array}$ & $\begin{array}{l}\text { Base paste: Methacrylate monomers containing phosphoric acid } \\
\text { groups, Methacrylate monomers, Silanated fillers, Initiator components, } \\
\text { Stabilizers, Rheological additives } \\
\text { Catalyst paste: Methacrylate monomers, Alkaline (basic) fillers, Silanated } \\
\text { fillers, Initiator components, Stabilizers, Pigments, Rheological additives }\end{array}$ \\
\hline RelyX ARC & 3M ESPE & $\begin{array}{l}\text { Dual-cure } \\
\text { conventional }\end{array}$ & $\begin{array}{l}\text { Paste A: Silane treated ceramic, Triethylene glycol-glycidyl methacrylate } \\
\text { (TEGDMA), Bisphenol glycidyl methacrylate (Bis-GMA), Silane treat- } \\
\text { ed silica, Functionalized dimethacrylate polymer, Triphenylantimony } \\
\text { Paste B: Silane treated ceramic, Triethylene glycol-glycidyl methacry- } \\
\text { late (TEGDMA), Bisphenol glycidyl methacrylate (Bis-GMA), Silane } \\
\text { treated silica, Functionalized dimethacrylate polymer, 2-benzotriazolyl- } \\
\text { 4-methylphenol, Benzoyl peroxide }\end{array}$ \\
\hline Multilink N & Ivoclar Vivadent & $\begin{array}{l}\text { Dual-cure } \\
\text { conventional }\end{array}$ & $\begin{array}{l}\text { Base }+ \text { Catalyst: Dimethacrylate, 2-hydroxyethyl methacrylate (HEMA), } \\
\text { Barium glass filler, Silicon dioxide filler, dibenzoyl peroxide, Ytterbium } \\
\text { trifluoride, Catalysts, Stabilizers, Pigments }\end{array}$ \\
\hline $\begin{array}{l}\text { G-CEM } \\
\text { LinkAce }\end{array}$ & GC & $\begin{array}{l}\text { Dual-cure } \\
\text { Self-adhesive }\end{array}$ & $\begin{array}{l}\text { Paste A: Fluoro-alumino-silicate glass, Urethanedimethacrylate, Di- } \\
\text { methacrylate, Silicon dioxide, Initiator, Inhibitor, Pigment } \\
\text { Paste B: Silicon dioxide, Urethanedimethacrylate, Dimethacrylate, Ini- } \\
\text { tiator, Inhibitor }\end{array}$ \\
\hline
\end{tabular}

Data from manufacturers's websites and/or product catalogs.

Table 2. Experimental groups of this study

\begin{tabular}{|c|c|c|}
\hline Cement & \multicolumn{2}{|c|}{ Experimental condition } \\
\hline \multirow[t]{2}{*}{ FujiCEM 2} & Immediate & Self-cured $(n=20)$ \\
\hline & $24 \mathrm{hr}$ & Self-cured $(n=20)$ \\
\hline \multirow[t]{4}{*}{ RelyX U200 } & Immediate & Self-cured $(\mathrm{n}=20)$ \\
\hline & & Light-cured $(n=20)$ \\
\hline & $24 \mathrm{hr}$ & Self-cured $(\mathrm{n}=20)$ \\
\hline & & Light-cured $(n=20)$ \\
\hline \multirow[t]{4}{*}{ RelyX ARC } & Immediate & Self-cured $(n=20)$ \\
\hline & & Light-cured $(\mathrm{n}=20)$ \\
\hline & $24 \mathrm{hr}$ & Self-cured $(n=20)$ \\
\hline & & Light-cured $(n=20)$ \\
\hline \multirow[t]{4}{*}{ Multilink N } & Immediate & Self-cured $(\mathrm{n}=20)$ \\
\hline & & Light-cured $(\mathrm{n}=20)$ \\
\hline & $24 \mathrm{hr}$ & Self-cured $(n=20)$ \\
\hline & & Light-cured $(n=20)$ \\
\hline \multirow[t]{4}{*}{ G-CEM LinkAce } & Immediate & Self-cured $(\mathrm{n}=20)$ \\
\hline & & Light-cured $(n=20)$ \\
\hline & $24 \mathrm{hr}$ & Self-cured $(n=20)$ \\
\hline & & Light-cured $(n=20)$ \\
\hline
\end{tabular}

고 mylar strip으로 덮은 뒤 유리판으로 누른 다음 LED 광중합기(G-Light, GC Co.)를 이용하여 주형의 양쪽면 에 각각 20 초간 광중합하였다. 즉시 광중합은 광중합 이 끝난 뒤 바로 강도를 측정하였고, 24시간 광중합은 $\mathrm{LED}$ 광중합 후 자가중합과 동일한 조건의 항온기에 24 시간동안 넣어 자가중합을 추가로 유도한 뒤 강도를 측 정하였다.

\section{4. 기계적 특성 측정}

시편을 testing table에 올려두고 만능 시험기(RB-306, R\&B Inc., Daejeon, Korea)를 이용하여 최대하중 $1 \mathrm{KN}$ 의 조건에서 1 분당 $0.5 \mathrm{~mm}$ 의 cross-head speed로 시멘 트가 파절되는 시점까지 최대힘 $(\mathrm{N})$ 을 측정하였다. 압 축강도와 간접인장강도는 다음 각각의 공식에 따라 Megapascal $(\mathrm{MPa})$ 로 계산하였다. 


$$
\text { Compressive strength }=4 p / \pi d^{2}
$$

여기서 $p$ 는 가해진 최대힘 $(\mathrm{N})$ 이고, $\mathrm{d}$ 는 측정된 시편의 직경 $(\mathrm{mm})$ 이다.

Diametral tensile strength $=2 P / \pi D T$

여기서 $P$ 는 가해진 최대힘 $(\mathrm{N}), D$ 는 시편의 직경 $(\mathrm{mm})$, $T$ 는 시편의 두께 $(\mathrm{mm})$ 이다.

\section{5. 통계 분석}

SPSS Ver 21.0 (SPSS Inc., Chicago, IL, USA)를 사용 하여 각 측정시점에서 동일한 시멘트의 중합방법에 따 른 압축강도와 간접인장강도를 $t$-test로 비교하였고, 각 시멘트간의 압축강도와 간접인장강도를 $95 \%$ 유의수준 에서 One way ANOVA test로 분석하였으며, Scheffe's test로 사후검정하였다.

\section{결과}

압축강도에서는 RelyX ARC의 광중합과 Multilink N 의 광중합, 간접인장강도에서는 RelyX ARC의 광중합을 제외하고 모든 중합방법에서 24시간뒤 측정된 강도가 즉시 측정한 강도보다 더 높은 값을 보여주었다(Table $3,4)$.

자가중합 방법에서 시멘트의 그룹간 통계적 차이를 살펴보기 위해 사후검정을 한 결과 압축강도와 간접인 장강도에서 레진강화형 글래스아이오노머인 Fujicem 2 가 통계적으로 유의하게 가장 낮은 값을 보였다 $(P<$ 0.05 , Table 5,6$)$.

압축강도에서는 RelyX ARC 자가중합, RelyX ARC 광중합, Multilink N 자가중합, Multilink N 광중합에서 측정시간에 따른 강도 비교시 통계적으로 유의한 차이 가 없었고, 24시간 뒤 다른 중합방법에서 측정한 압축강 도는 RelyX ARC, Multilink N, G-CEM LinkAce에서 통

Table 3. Compressive strength of several cements according to curing modes and measured time [Mean (MPa) and Standard deviation]

\begin{tabular}{cllcc}
\hline \multicolumn{1}{c}{ Group } & & N & Immediate & $24 \mathrm{hr}$ \\
\hline FujiCEM 2 & Self-cured & 20 & $64.15 \pm 4.37$ & $203.10 \pm 45.85$ \\
RelyX U200 & Self-cured & 20 & $220.50 \pm 57.29$ & $362.55 \pm 44.96$ \\
& Light-cured & 20 & $360.30 \pm 49.73$ & $407.65 \pm 47.54$ \\
RelyX ARC & Self-cured & 20 & $430.45 \pm 50.24$ & $463.45 \pm 57.94$ \\
& Light-cured & 20 & $478.75 \pm 21.42$ & $467.45 \pm 47.13$ \\
Multilink N & Self-cured & 20 & $500.95 \pm 62.71$ & $511.65 \pm 61.89$ \\
& Light-cured & 20 & $542.40 \pm 49.95$ & $511.25 \pm 78.73$ \\
G-CEM LinkAce & Self-cured & 20 & $498.70 \pm 53.23$ & $580.75 \pm 40.62$ \\
& Light-cured & 20 & $430.40 \pm 56.63$ & $559.05 \pm 53.88$ \\
\hline
\end{tabular}

Table 4. Diametral tensile strength of several cements according to curing modes and measured time [Mean (MPa) and Standard deviation]

\begin{tabular}{cllcc}
\hline \multicolumn{1}{c}{ Group } & & N & Immediate & $24 \mathrm{hr}$ \\
\hline FujiCEM 2 & Self-cured & 20 & $10.20 \pm 2.21$ & $26.65 \pm 6.12$ \\
RelyX U200 & Self-cured & 20 & $15.15 \pm 3.84$ & $49.80 \pm 6.44$ \\
& Light-cured & 20 & $62.55 \pm 10.93$ & $76.20 \pm 11.41$ \\
RelyX ARC & Self-cured & 20 & $60.75 \pm 11.46$ & $86.55 \pm 11.92$ \\
& Light-cured & 20 & $88.85 \pm 8.01$ & $88.60 \pm 16.10$ \\
Multilink N & Self-cured & 20 & $77.60 \pm 25.00$ & $88.05 \pm 7.94$ \\
& Light-cured & 20 & $97.25 \pm 15.78$ & $104.70 \pm 8.62$ \\
G-CEM LinkAce & Self-cured & 20 & $73.35 \pm 16.48$ & $111.45 \pm 15.61$ \\
& Light-cured & 20 & $77.75 \pm 17.88$ & $109.90 \pm 14.04$ \\
\hline
\end{tabular}


Table 5. Scheffe's test result of compressive strength in inter-cements according to same curing mode and measured time [Mean (MPa)]

\begin{tabular}{cccccc}
\hline & \multirow{2}{*}{ N } & \multicolumn{2}{c}{ Immediate } & \multicolumn{2}{c}{$24 \mathrm{hr}$} \\
& Self-cured & Light-cured & Self-cured & Light-cured \\
\hline FujiCEM 2 & 20 & $64.15^{\mathrm{a}}$ & - & $203.10^{\mathrm{a}}$ & - \\
RelyX U200 & 20 & $222.50^{\mathrm{b}}$ & $360.30^{\mathrm{a}}$ & $362.55^{\mathrm{b}}$ & $407.65^{\mathrm{a}}$ \\
RelyX ARC & 20 & $430.45^{\mathrm{c}}$ & $478.75^{\mathrm{c}}$ & $463.45^{\mathrm{c}}$ & $467.45^{\mathrm{b}}$ \\
Multilink N & 20 & $498.70^{\mathrm{d}}$ & $542.40^{\mathrm{d}}$ & $511.65^{\mathrm{c}}$ & $511.25^{\mathrm{c}}$ \\
G-CEM LinkAce & 20 & $500.95^{\mathrm{d}}$ & $430.40^{\mathrm{b}}$ & $580.75^{\mathrm{d}}$ & $559.05^{\mathrm{c}}$ \\
\hline
\end{tabular}

Means followed by superscript letters are significantly different $(P<0.05)$ cements, representing same curing mode (vertical comparisons).

Table 6. Scheffe's test result of diametral tensile strength in inter-cements according to same curing mode and measured time $[\mathrm{Mean}(\mathrm{MPa})]$

\begin{tabular}{cccccc}
\hline & \multirow{2}{*}{ N } & \multicolumn{2}{c}{ Immediate } & \multicolumn{2}{c}{$24 \mathrm{hr}$} \\
& Self-cured & Light-cured & Self-cured & Light-cured \\
\hline FujiCEM 2 & 20 & $10.20^{\mathrm{a}}$ & - & $26.65^{\mathrm{a}}$ & - \\
RelyX U200 & 20 & $15.15^{\mathrm{a}}$ & $62.55^{\mathrm{a}}$ & $49.80^{\mathrm{b}}$ & $76.20^{\mathrm{a}}$ \\
RelyX ARC & 20 & $60.75^{\mathrm{b}}$ & $88.85^{\mathrm{b}, \mathrm{c}}$ & $86.55^{\mathrm{c}}$ & $88.60^{\mathrm{b}}$ \\
Multilink N & 20 & $77.60^{\mathrm{c}}$ & $97.25^{\mathrm{c}}$ & $111.45^{\mathrm{d}}$ & $104.70^{\mathrm{c}}$ \\
G-CEM LinkAce & 20 & $73.35^{\mathrm{b}, \mathrm{c}}$ & $77.75^{\mathrm{b}}$ & $88.05^{\mathrm{c}}$ & $109.90^{\mathrm{c}}$ \\
\hline
\end{tabular}

Means followed by superscript letters are significantly different $(P<0.05)$ cements, representing same curing mode (vertical comparisons).

Table 7. Scheffe's test result of compressive strength in intra-cements according to different curing mode and measured time $[\mathrm{Mean}(\mathrm{MPa})]$

\begin{tabular}{llcccc}
\hline & & RelyX U200 & RelyX ARC & Multilink N & G-CEM LinkAce \\
\hline \multirow{2}{*}{ Immediate } & Self-cured $(\mathrm{n}=20)$ & $220.50^{\mathrm{a}}$ & $430.45^{\mathrm{a}}$ & $500.95^{\mathrm{a}}$ & $498.70^{\mathrm{b}}$ \\
& Light-cured $(\mathrm{n}=20)$ & $360.30^{\mathrm{b}}$ & $478.75^{\mathrm{b}}$ & $542.40^{\mathrm{a}}$ & $430.40^{\mathrm{a}}$ \\
\multirow{2}{*}{24 hours } & $362.55^{\mathrm{b}, \mathrm{c}}$ & $463.45^{\mathrm{a}}$ & $511.65^{\mathrm{a}}$ & $580.75^{\mathrm{c}}$ \\
& Self-cured $(\mathrm{n}=20)$ & $407.65^{\mathrm{c}}$ & $467.45^{\mathrm{a}, \mathrm{b}}$ & $511.25^{\mathrm{a}}$ & $559.05^{\mathrm{c}}$ \\
\hline
\end{tabular}

Means followed by superscript letters are significant difference $(P<0.05)$ in different curing mode (vertical comparisons).

Table 8. Scheffe's test result of diametral tensile strength in intra-cements according to different curing mode and measured time $[\mathrm{Mean}(\mathrm{MPa})]$

\begin{tabular}{llcccc}
\hline & & RelyX U200 & RelyX ARC & Multilink N & G-CEM LinkAce \\
\hline \multirow{2}{*}{ Immediate } & Self-cured $(\mathrm{n}=20)$ & $15.15^{\mathrm{a}}$ & $60.75^{\mathrm{a}}$ & $77.60^{\mathrm{a}}$ & $73.35^{\mathrm{a}}$ \\
& Light-cured $(\mathrm{n}=20)$ & $62.55^{\mathrm{c}}$ & $88.85^{\mathrm{b}}$ & $97.25^{\mathrm{b}, \mathrm{c}}$ & $77.75^{\mathrm{a}}$ \\
\multirow{2}{*}{24 hours } & Self-cured $(\mathrm{n}=20)$ & $49.80^{\mathrm{b}}$ & $86.55^{\mathrm{b}}$ & $88.05^{\mathrm{a}, \mathrm{b}}$ & $111.45^{\mathrm{b}}$ \\
& Light-cured $(\mathrm{n}=20)$ & $76.20^{\mathrm{d}}$ & $88.85^{\mathrm{b}}$ & $104.70^{\mathrm{c}}$ & $109.90^{\mathrm{b}}$ \\
\hline
\end{tabular}

Means followed by superscript letters are significant difference $(P<0.05)$ in different curing mode (vertical comparisons).

계적으로 유의한 차이가 없었다(Table 7).

간접인장강도에서는 RelyX ARC 광중합, Multilink N 자가중합, Multilink N 광중합에서 측정시간에 따른 강 도 비교시 통계적으로 유의한 차이가 없었고, 다른 중
합방법에서 비교시 24시간후 RelyX ARC, 24시간후 G-CEM LinkAce, 즉시 G-CEM LinkAce에서 측정한 간접인장강도 값이 통계적으로 유의한 차이가 없었다 (Table 8). 


\section{고찰}

레진 시멘트의 기계적인 성질 중 압축강도를 측정할 때, 시편의 형상이 변하거나 압축 과정에서 시편에 굽힘 이 발생하면 강도 값이 실제 값보다 낮게 측정되는 문 제가 발생할 수 있다. ${ }^{4}$ 또한 간접인장강도를 측정할 때 도 파절 전 시편의 형상이 심하게 변형되는 경우에는 측 정 값이 인장응력에 의한 것인지 변형을 일으키는 전단 응력에 의한 것인지 구분할 수 없는 문제가 존재한다. ${ }^{4,17}$ 따라서 이번 실험 과정에서 강도를 측정할 때 시편의 형 상이 미세하게 변하였더라면 측정 값이 실제 값과는 다 르게 측정되었을 가능성이 높을 것으로 생각된다.

압축강도에서는 RelyX ARC의 광중합과 Multilink N 의 광중합, 간접인장강도에서는 RelyX ARC의 광중합 을 제외하고, 나머지 압축강도와 간접인장강도는 즉 시 측정한 값보다 24시간 뒤 측정한 값이 더 높게 나 타났다. 그 이유는 기계적 성질이 중합체(polymer)의 cross-linking과 중합반응 동안 형성되는 network의 질 (quality)에 의존하기 때문이며, ${ }^{18}$ 또한 시간이 증가할수 록 중합반응이 증가하기 때문에 더 높은 강도 값을 나타 냈다고 생각할 수 있다.

레진 시멘트 중에 광중합형은 연장된 작업시간과 필 요에 따라 조절가능한 경화시간, 향상된 색조안정성의 임상적 장점을 가지고 있으나, 빛 도달 여부에 따른 수 복물 두께의 제한이 있다. ${ }^{19}$ 따라서 빛이 잘 도달되지 않 는 간접 수복물 접착시에는 광중합과 자가중합이 모두 일어나는 이중중합 레진 시멘트를 사용하게 된다. ${ }^{20}$ 이 번 실험에 사용한 레진 시멘트에서 전반적으로 광중합 후 그리고 24시간이 지난 뒤 측정한 강도값이 자가중합 후 즉시 측정한 값보다 높게 나타났다. 이는 자가중합이 활성화 되기 위해서는 시간이 필요하며 같은 시간이 주 어진다고 가정한다면 광중합과 자가중합 모두가 발생 해야 더 많은 중합반응이 일어난다고 생각할 수 있다. 그러나 Manso AP 등의 연구에서는 이중중합 시멘트 에서 광중합 활성이 자가중합 반응을 방해하고 시멘트 의 최대 기계적 성질을 제한하는 경향이 있음을 보고한 바 있다. ${ }^{19,20}$ 본 실험 결과에서도 압축시험에서 G-CEM LinkAce 레진 시멘트의 경우, 측정 시간에 따라 광중합 (즉시 측정값: $430.40 \pm 56.63 \mathrm{MPa}, 24$ 시간 뒤 측정값: $559.05 \pm 53.88 \mathrm{MPa}$ ) 보다 자가중합의 강도값(즉시 측 정값: $498.70 \pm 53.23 \mathrm{MPa}, 24$ 시간 뒤 측정값: $580.75 \pm$ $40.62 \mathrm{MPa}$ )이 더 큼을 볼 수 있었다(Table 3). 제조사에
따르면 이중중합 레진 시멘트 사용할 때에는 항상 광중 합 사용을 추천 하고 있는데, 기계적인 측면에서 살펴볼 때 이 결과는 임상적으로 중요한 의미를 가진다. 즉 이 는 임상적으로 이중중합 레진 시멘트를 사용할 때 가능 한 최대시간으로 자가중합을 한 후 광중합을 고려해야 함을 암시한다..$^{20}$ 그러나 더 자세히 평가하기 위해서는 추가적인 연구가 필요할 것이다.

이번 실험의 연구 결과 전통적인 이중중합 레진 시멘 트인 RelyX ARC와 Multilink N은 압축강도에서 광중합 후 즉시 측정값이 자가중합 후 즉시 측정한 값보다 유의 하게 높은 값을 보여주었다 $(P<0.05)$. 이는 자가중합이 광중합보다 항상 낮은 중합을 보인다는 결과와 일치한 다. ${ }^{21}$ 하지만, 24 시간이 경과 후 광중합과 24시간이 경과 후 자가중합의 측정값은 자가중합 후 즉시 측정한 값보 다는 높은 값을 보여주지만 광중합 후 즉시 측정한 값보 다는 낮은 값을 나타내어 24시간이 지난 뒤에는 중합방 법에 따른 강도 차이가 없음을 보여준다(Table 3).

실험 결과에서 G-CEM LinkAce의 압축강도와 간접 인장강도가 다른 이중중합 레진 시멘트에 비해 비교적 높은 강도 값을 보였는데, 그 이유를 시멘트의 구성성분 인 urethanedimethacrylate (UDMA)의 사용으로 생각해 볼 수 있다. 레진 시멘트의 필러 함량은 이론적으로 물 질의 강도, 수분 흡수의 저항, 압입 저항, 마모 저항, 중 합수축과 관련이 있다는 연구결과가 있다. ${ }^{12}$ 레진 시멘 트의 높은 기계적 성질은 일차적으로 레진 종류와 레 진 기질의 구성 성분, 필러 종류와 필러 함유량에 영향 을 받으며, 필러 입자는 레진 기질 자체보다 더 뛰어난 기계적인 성질을 제공한다. ${ }^{2}$ 또한 레진 시멘트의 물리 적인 성질은 중합 메커니즘과 더불어 중합과 무기질 상 (phase)의 양과 질의 차이로 다양해질 수 있다. ${ }^{12}$ 시멘트 G-CEM LinkAce의 구성성분인 UDMA는 점도가 낮아 저분자량의 단량체를 첨가하지 않아도 많은 양의 필러 가 함유되어 강도가 크게 측정되었다고 생각된다. ${ }^{22}$

이중중합 자가접착 레진 시멘트인 RelyX U200과 G-CEM LinkAce는 같은 중합방법에서 즉시 측정된 값 보다 24시간 뒤 측정한 강도 값이 더 높았다. 또한 RelyX U200은 광중합 후 24시간 뒤 측정 값이 가장 높으나 G-CEM LinkAce는 자가중합 후 24시간 뒤 측정한 값이 가장 높게 측정되었다. 이는 시간이 지남에 따라 자가중 합이 계속 일어나며 제품마다 다른 구성요소가 강도에 영향을 미친다고 유추할 수 있다(Table 3,4$)$. 하지만 이 러한 원인을 설명하기 위해 제조사가 제공하는 자료를 
바탕으로 자세한 구성성분과 함량을 알아보려고 하였으 나 공개된 정보가 적거나 없고, 아직까지 새롭게 출시된 재료에 대한 연구가 미흡하여, 제품 정보를 구하고 이를 설명하기에 어려움이 있다.

일반적으로 레진강화형 글래스아이오노머 시멘트 는 polyalkenoic acid의 수용액과 fluoroaluminosilicate glass powder 사이의 산-염기 반응에 의해 경화된다. ${ }^{23}$ 레진강화형 글래스아이오노머 시멘트는 전통 글래스 아이오노머 시멘트, 인산아연 시멘트와 비교시 높은 압 축강도와 간접인장강도를 가진다는 연구결과가 있다. ${ }^{12}$ 본 실험에서 사용한 이중중합 자가접착 레진 시멘트인 G-CEM LinkAce는 제조사가 제시한 구성성분으로 보 면 레진강화형 글래스아이오노머와 같은 시멘트 분류에 속할 것으로 보이나, 실험결과 강도 측면에서 레진강화 형 글래스아이오노머 시멘트의 강도와 큰 차이를 보인 다(Table $1,3,4)$. 이를 설명하기 위해 각 제품의 구체적 인 성분의 차이를 알아보려 하였으나 제조사에서 제공 하는 정보에는 자세한 구성 성분이 나타나지 않고, 이를 분석한 연구도 아직까지 없는 실정이어서 설명하기 어 렵다.

최근 자가접착 레진 시멘트는 전처리 과정이 필요하 지 않고 한 단계의 과정만으로 간접수복물을 합착하기 때문에 임상에서 편의성과 시간 절약의 장점으로 인기 를 끌고 있다. ${ }^{8} 2002$ 년도에 첫 출시된 자가접착 레진 시 멘트인 RelyX Unicem (3M ESPE) 이란 상품은 단량체 에 인산기를 반응기로 가지고 있어서 치아의 수산화인 회석으로부터 칼슘 이온과 반응하여 화학 결합을 이루 고, ${ }^{24}$ 산성기(acidic group)는 염기성 무기물인 필러와 화 학적으로 산-염기 중합반응을 일으켜 결합하는 메커니 즘을 가진다. ${ }^{8,25}$ 제조사의 정보에 따르면 RelyX Unicem Clicker의 압축강도는 자가중합시 $216 \mathrm{MPa}$, 광중합시 $244 \mathrm{MPa}$ 라고 하며 RelyX U200은 RelyX Unicem의 업 그레이드 된 제품으로, RelyX U200의 압축강도는 291 $\mathrm{MPa}$ 라고 한다. 실험 결과에서 RelyX U200의 압축강도 는 자가중합 후 즉시 측정값은 $200.50 \pm 57.29 \mathrm{MPa}$, 광 중합 후 즉시는 $360.30 \pm 49.73 \mathrm{MPa}$, 자가중합 후 24시 간 뒤는 $362.55 \pm 44.96 \mathrm{MPa}$, 광중합 후 24시간 뒤는 $407.65 \pm 47.54 \mathrm{MPa}$ 값으로 즉시 자가중합을 제외하면 제조사의 수치보다 큰 값을 보인다(Table 3). 이러한 차 이를 보이는 이유는 실험 환경과 실험자, 표본수 등의 차이 때문일 것이다.

이번 연구에서는 이중중합 레진 시멘트의 중합 방법
에 따라 측정 시기를 즉시와 24시간으로 나눠 살펴보았 으나, 장기적인 수복물의 예후 측정을 위해 더 긴 기간 을 추가로 측정해 보는 것이 필요할 것으로 생각된다. 또한 레진 시멘트의 강도는 수분에 큰 영향을 받기 때문 에 추가적으로 구강내 환경을 설정하여 실험해보는 것 도 필요할 것으로 생각된다.

압축강도와 간접인장강도는 단지 치과용 시멘트 선 택시 고려되는 2 가지의 기계적 성질의 기준이 되며 결 정적인 것은 아니다. 강력한 시멘트는 스트레스 분산이 좋고, 보철물 탈락 실패의 가능성이 적으며, 임상적으로 성공 가능성을 높여준다. 현재 이중중합 자가접착 레진 시멘트에 대한 임상적인 연구는 짧은 기간의 연구에 관 한 것만 있기 때문에 유의한 임상적 효과를 판별하기 어 렵다. 현재는 참고자료가 부족한 상황이며, 앞으로 추가 적인 연구가 진행되어 재료 선택시 도움이 되는 자료를 만들어야 할 것이다. 또한 고정성 수복물의 접착을 위해 시멘트를 선택할 때 다른 여러 기계적인 성질과 생체적 합성, 시술후 과민증, 심미성, 사용 편의성 등의 복합적 인 요소가 고려해야만 할 것이다.

\section{결론}

치과용 시멘트 중에서 최근 출시된 이중중합 자가접 착 레진 시멘트는 기존의 레진 시멘트와 비교시 제품별 로는 차이가 있었으나 압축강도와 간접인장강도에서 유 의한 차이를 보이지 않았다. 이번 결과는 임상에서 레진 시멘트의 유용한 사용을 위한 하나의 기초자료가 될 수 있을 것으로 사료된다.

\section{Acknowledgements}

이 논문은 2013년도 강릉원주대학교 학술연구조성비 지원에 의하여 수행되었다.

\section{References}

1. The korean academy of conservative dentistry. Operative dentistry. $4^{\text {th }}$ ed. Seoul; DaehanNarae publibhing Inc.; 2003. p. 217-20.

2. Piwowarczyk A, Lauer HC. Mechanical properties of luting cements after water storage. Oper Dent 2003;28:535-42. 
3. Li ZC, White SN. Mechanical properties of dental luting cements. J Prosthet Dent 1999;81:597-609.

4. The korea professor conference for dental materials. Dental materials. $4^{\text {th }}$ ed. Seoul; Koonja publishing Inc.; 2006. p. 46-50, 237-8.

5. Rosenstiel SF, Land MF, Crispin BJ. Dental luting agents: a review of the current literature. J Prosthet Dent 1998;80:280-301.

6. Smales RJ, Webster DA. Restoration deterioration related to later failure. Oper Dent 1993;18:130-7.

7. de la Macorra JC, Pradíes G. Conventional and adhesive luting cements. Clin Oral Investig 2002;6: 198-204.

8. Ferracane JL, Stansbury JW, Burke FJ. Self-adhesive resin cements - chemistry, properties and clinical considerations. J Oral Rehabil 2011;38:295-314.

9. Yüzügüllü B, Ciftçi Y, Saygili G, Canay S. Diametral tensile and compressive strengths of several types of core materials. J Prosthodont 2008;17:102-7.

10. Cattani-Lorente MA, Godin C, Meyer JM. Early strength of glass ionomer cements. Dent Mater 1993;9:57-62.

11. Ban S, Hasegawa J, Anusavice KJ. Effect of loading conditions on bi-axial flexure strength of dental cements. Dent Mater 1992;8:100-4.

12. White SN, Yu Z. Physical properties of fixed prosthodontic, resin composite luting agents. Int J Prosthodont 1993;6:384-9.

13. Canay S, Hersek N, Akça K, Ciftçi Y. The effect of weight loss of liquid on the diametral tensile strengths of various kinds of luting cements. Int Dent J 1996;46:52-8.

14. Scherrer SS, de Rijk WG, Belser UC, Meyer JM. Effect of cement film thickness on the fracture resistance of a machinable glass-ceramic. Dent Mater 1994;10:172-7.
15. Mueller HJ. Fracture toughness and fractography of dental cements, lining, build-up, and filling materials. Scanning Microsc 1990;4:297-307.

16. Editor. Book ISO Specifications 9917-1. City; 2007. Chapter Chapter, ISO Specifications 9917-1.

17. Yap AU, Cheang PH, Chay PL. Mechanical properties of two restorative reinforced glass-ionomer cements. J Oral Rehabil 2002;29:682-8.

18. Ferracane JL. Correlation between hardness and degree of conversion during the setting reaction of unfilled dental restorative resins. Dent Mater 1985; 1:11-4.

19. Pegoraro TA, da Silva NR, Carvalho RM. Cements for use in esthetic dentistry. Dent Clin North Am 2007;51:453-71, x.

20. Manso AP, Silva NR, Bonfante EA, Pegoraro TA, Dias RA, Carvalho RM. Cements and adhesives for all-ceramic restorations. Dent Clin North Am 2011; 55:311-32, ix.

21. Rueggeberg FA, Caughman WF. The influence of light exposure on polymerization of dual-cure resin cements. Oper Dent 1993;18:48-55.

22. Song CK, Park SH, Kim JW, Cho KM. Physical properties of different automixing resin cements and the shear bond strength on dentin. J Dent Rehabil Appl Sci 2009;25:435-42.

23. Diaz-Arnold AM, Vargas MA, Haselton DR. Current status of luting agents for fixed prosthodontics. J Prosthet Dent 1999;81:135-41.

24. Gerth HU, Dammaschke T, Züchner H, Schäfer E. Chemical analysis and bonding reaction of RelyX Unicem and Bifix composites-a comparative study. Dent Mater 2006;22:934-41.

25. Vrochari AD, Eliades G, Hellwig E, Wrbas KT. Curing efficiency of four self-etching, self-adhesive resin cements. Dent Mater 2009;25:1104-8. 


\section{중합방법에 따른 여러 이중중합 레진 시멘트의 기계적 성질 평가}

\section{김수연, 박세희, 김진우, 조경모*}

강릉원주대학교 치과대학 치과보존학교실

목적: 중합방법 및 측정시기에 따른 여러 이중중합 레진 시멘트의 기계적 성질인 압축강도와 간접인장강도를 비교 평 가하는 것이다.

연구 재료 및 방법: 1 개의 레진강화형 글래스아이오노머 시멘트인 FujiCEM 2, 2개의 전통적인 이중중합 레진 시멘트 인 RelyX ARC와 Multilink N, 2개의 이중중합 자가접착 레진 시멘트인 RelyX U200과 G-CEM LinkAce를 사용하였다. 제조사의 지시에 따라 시멘트를 혼합하여 압축강도와 간접인장강도 측정을 위한 시편을 제작하였다. 중합방법 및 측정 시기의 영향을 평가하기 위해 시멘트에 따라 4가지 실험 조건으로 나눴고, 만능시험기로 압축강도와 간접인장강도 측 정하였다. 각각의 강도 값을 계산 후 통계처리 하였다.

결과: 압축강도에서는 RelyX ARC의 광중합과 Multilink N의 광중합, 간접인장강도에서는 RelyX ARC의 광중합을 제 외하고 모든 중합방법에서 24시간 뒤 측정된 강도가 즉시 측정한 강도보다 더 높은 값을 보여주었다. FujiCEM 2는 시 멘트간 비교에서 가장 낮은 강도 값을 보였다 $(P<0.05)$.

결론: 치과용 시멘트 중에서 최근 출시된 이중중합 자가접착 레진 시멘트는 기존의 레진 시멘트와 비교시 제품별로 차 이가 있었으나, 압축강도와 간접인장강도에서는 유의한 차이를 보이지 않았다.

(구강회복응용과학지 2015;31(1):1-9)

주요어: 레진 시멘트; 이중중합; 자가접착; 압축강도; 간접인장강도; 중합방법

*교신저자: 조경모

(210-702) 강원도 강릉시 죽헌길 7 강릉원주대학교 치과대학 치과보존학교실

Tel: 033-640-3155 | Fax: 033-640-3103 | E-mail: drbozon@gwnu.ac. kr

접수일: 2014년 10월 27일 | 수정일: 2015년 2월 3일 | 채택일: 2015년 1월 8일 